\title{
THERAPEUTIC DRUG MONITORING (TDM) OF VORICONAZOLE IN HAEMATOLOGIC MALIGNANCY PATIENTS
}

Neha Sharad 1 , Gagandeep Singh ${ }^{1}$, Immaculata Xess' ${ }^{1}$, Reshu Agarwal ${ }^{1}$, Tulika Seth ${ }^{2}$, K.H. Reeta ${ }^{3}$

1Department of Microbiology, ${ }^{2}$ Department of Haematology, ${ }^{3}$ Department of Pharmacology All India Institute of Medical Sciences, New Delhi, India

\section{OBJECTIVE}

Objective of the study was to monitor trough voriconazole serum levels in patients with haematological malignancy with clinically suspected invasive fungal infections

\section{BACKGROUND}

* Invasive fungal infections (IFIs): Important cause of concern in immuno-compromised people owing to high mortality and morbidity, particularly in neutropenic patients with hematological malignancies

* Antifungal agents available for treating invasive fungal infections: polyenes, azoles, and echinocandins

* Triazoles: Susceptibility more variable, depends on specific agent

* Voriconazole: Large and unpredictable variations in drug plasma concentrations, follows non-linear pharmacokinetics

\section{METHODOLOGY}

* Study: March 2016 to October 2017

* Patients with haematologic malignancies: With clinically suspected IFIs being treated with only voriconazole

* All the demographic and clinical details of the patients were noted

* Sample: Trough serum levels on day 5 after start of voriconazole

* Analysis: Bioassay

* In case of dose alterations following sub and supratherapeutic levels, TDM was repeated on day 5

* Clinicians were informed and proper interventions were made according to levels and clinical condition of patients

\section{RESULTS}

* Total of 39 patients were evaluated, 15 children and 24 adults

* AML: Most common underlying malignancy

* Fungal pneumonia: Most common IFI

* All cases were either possible or probable case of IFI

- Major risk factor: Neutropenia due to chemotherapy sessions

* After first TDM: 15/39 had levels <1 mg/l, 20/39 had levels in between 1 and $6 \mathrm{mg} / \mathrm{l}, 4 / 39 \mathrm{had}>6 \mathrm{mg} / \mathrm{l}$

* Overall successful outcome after evaluation by TDM and dose alterations seen in $86 \%$

* Side effects developed in $5 / 39$ patients (12.8\%)

\section{CONCLUSION}

* Only half of our patients had voriconazole serum levels within therapeutic range after first dose

* Dose alterations were done in rest for achieving recommended serum levels

* Thus, we recommend TDM for all patients of hematologic malignancy receiving voriconazole for appropriate management

\section{REFERENCES}

* Montagna MT, De Giglio O, Napoli C, Lovero G, Caggiano G, Delia $M$, et al. Invasive fungal infections in patients with hematologic malignancies (aurora project): lights and shadows during 18-months surveillance. Int $\mathrm{J}$ Mol Sci. 2012;13(1):774-87.

* Lipp HP. Antifungal agents--clinical pharmacokinetics and drug interactions. Mycoses. 2008;51 Suppl 1:7-18.

- Maertens J, Meersseman W, Van Bleyenbergh P. New therapies for fungal pneumonia. Curr Opin Infect Dis. 2009

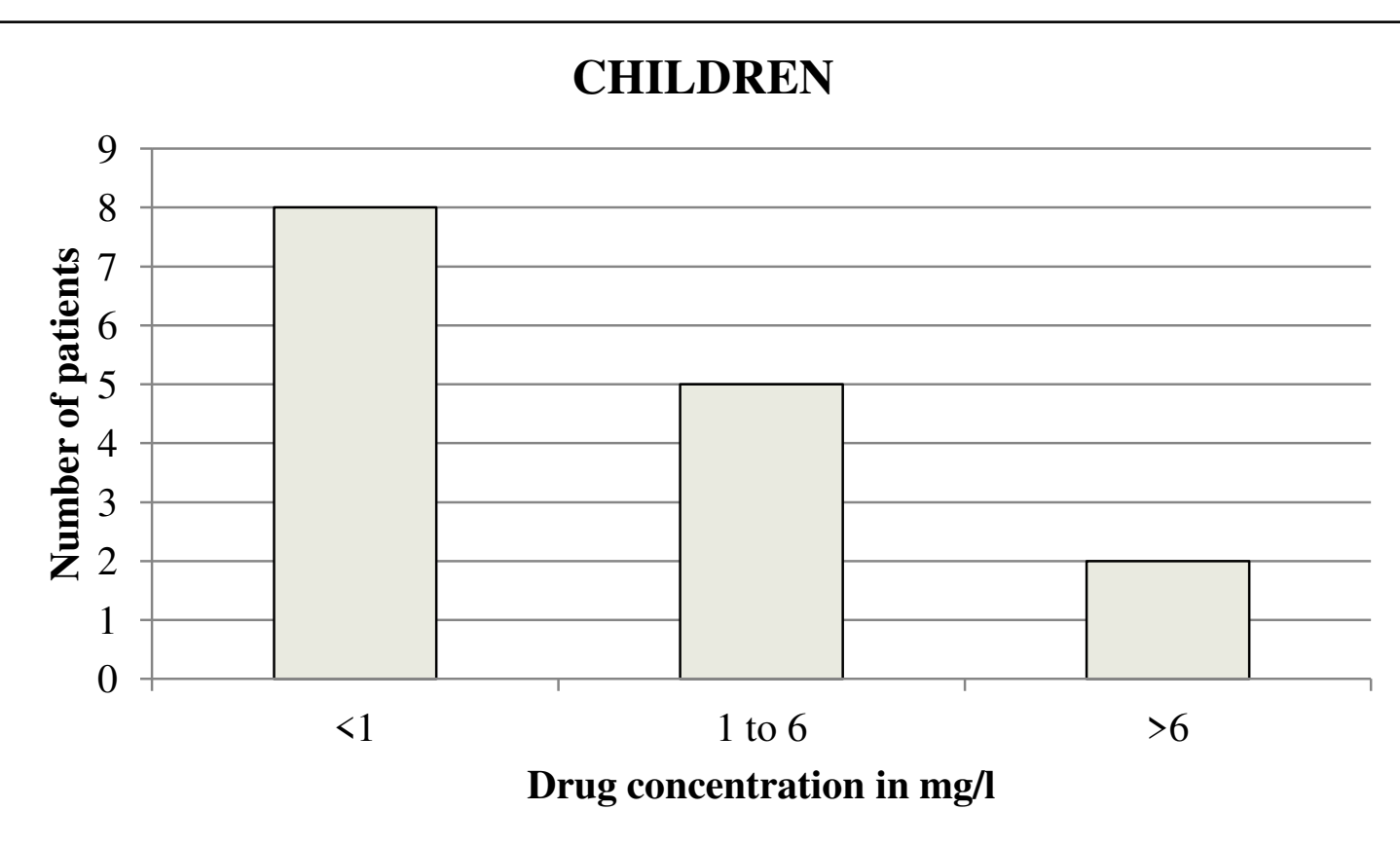

Distribution of TDM levels in children: $<1 \mathrm{mg} / \mathrm{l}$ - subtherapeutic, $1-6 \mathrm{mg} / \mathrm{l}$ - therapeutic and $>6 \mathrm{mg} / \mathrm{l}$ - supratherapeutic

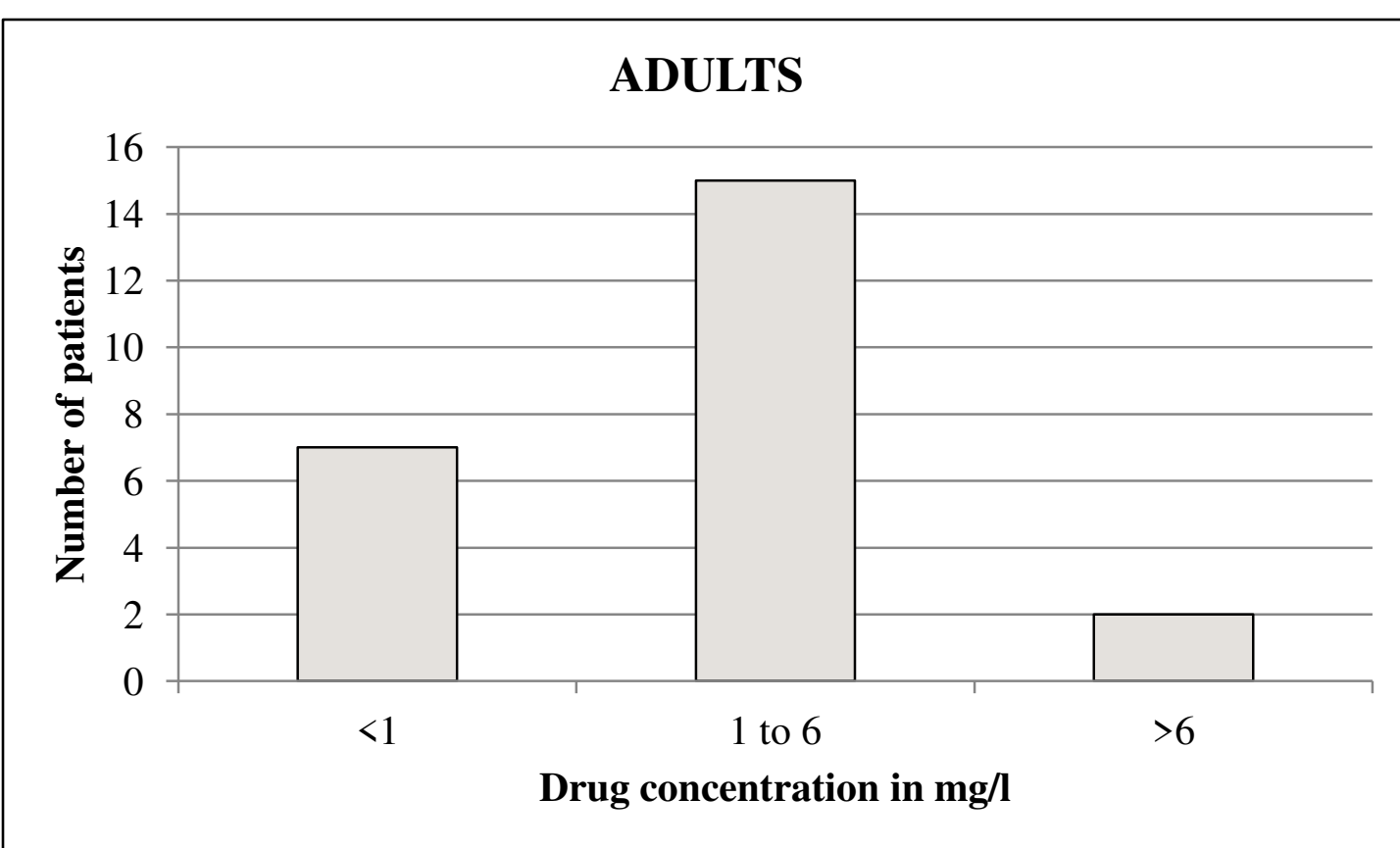

Distribution of TDM levels in adults: : $<1 \mathrm{mg} / \mathrm{I}$ - subtherapeutic, $1-6 \mathrm{mg} / \mathrm{I}$ - therapeutic and $>6 \mathrm{mg} / \mathrm{I}$ - supratherapeutic 